\title{
Jogando com as máquinas: relação entre videogames violentos e cognições agressivas
}

\section{Playing with the machines: the relationship between violent video games and aggressive cognitions}

\author{
Esther Sampaio Santos ${ }^{1}$ \\ Rogério Fernandes Santos ${ }^{2}$ \\ Máyra Ribeiro ${ }^{3}$
}

\begin{abstract}
RESUMO: O presente artigo objetivou verificar a relação entre a preferência por conteúdos violentos e hábitos relacionados aos jogos de videogames com a tendência a cognições agressivas. Para participar do estudo, era necessário que os participantes tivessem conta na rede social Facebook. Não só jogadores puderam participar, contanto que fossem maiores de idade. $O$ instrumento de levantamento de cognições foi criado no aplicativo online Google Docs. No instrumento, os participantes completaram algumas palavras dispostas e preencheram perguntas a respeito de hábitos de jogo e o quanto estes fazem parte de sua rotina, seus pensamentos e suas interações sociais. Para avaliar cognições agressivas, foram apresentados 12 conjuntos de letras no qual cada um deles exibia uma sequência com uma lacuna a ser completada, por exemplo, S_CO, cabendo as respostas SACO, SUCO, SOCO ou SECO. Foram verificados, ainda, os hábitos de jogo e as características sócio demográficas dos participantes. A partir dos resultados obtidos, pôde-se concluir que não houve significância na relação entre a preferência por games de conteúdo violento e cognições agressivas.
\end{abstract}

Palavras-chave: jogos eletrônicos; cognições agressivas; violência; agressividade; jogos eletrônicos violentos.

\begin{abstract}
This paper aimed verify the relationship between preference for violent content and habits related to videogames games with the tendency to aggressive cognitions. To participate in the study, it was necessary that the participants had account on the Facebook social network. Not only players were able to participate, provided they were of legal age. The cognitions survey instrument was created in the online application Google Docs. In the instrument, participants completed a few submitted words and answered questions about gambling habits and how these are part of your routine, your thoughts and your social interactions. To assess aggressive cognitions, they were submitted 12 sets of letters in which each exhibited a sequence with a gap to be completed, e.g. S_CO fitting responses SACO, SUCO, SOCO or SECO. They were checked also habits of play and sociodemographic characteristics of the participants. From the results obtained, it could be concluded that there was no significance in the relationship between preference for violent content of games and aggressive cognitions.
\end{abstract}

Keywords: videogames; aggressive cognitions; violence; aggressiveness; violent videogames.

\footnotetext{
${ }^{1}$ Mestranda do Programa de Pós-graduação em Psicologia na Universidade Federal de São João Del-Rei (UFSJ) - São João DelRei, MG, Brasil. E-mail: esther.sampaio2@yahoo.com.br.

2 Mestre em Psicologia; Docente do Programa de Graduação em Letras na Universidade Federal do Tocantins (UFTO) Araguaína, TO, Brasil.

${ }^{3}$ Mestre em Educação Especial; Docente do Programa de Graduação em Psicologia na Universidade Federal da Bahia (UFBA) Vitória da Conquista, BA, Brasil.
} 


\section{Introdução}

Os jogos eletrônicos vêm ganhando espaço em relação às pesquisas e discussões entre cientistas sociais sobre seus possíveis efeitos no comportamento humano. Termos como "simuladores de assassinos" ou "veneno digital", vêm sendo usados por políticos e advogados ao se referirem aos videogames (Ferguson, Miguel, Garza, \& Jerabeck, 2012). Porém, além de grande parte destes apontarem apenas para os efeitos negativos dos games, pesquisas que buscam falar a este respeito não são realizadas no Brasil, a não ser em contextos pedagógicos, olhando os jogos eletrônicos como utilitários educativos. Por exemplo, em estudo realizado por Alves (2009) objetivou-se verificar os efeitos da inserção de videogames como instrumento educacional. Foi concluído que o videogame foi um instrumento que melhorou a atenção dos participantes no âmbito escolar. A investigação aqui delineada permite inseri-lo no escopo das pesquisas em psicologia tornando os jogos de videogame, incluindo seu conteúdo e mecânicas de interação, um objeto a ser analisado com os conceitos da psicologia. Além disso, em termos teóricos é importante incluir uma atividade tão diversa e de uso crescente na sociedade como são os videogames dentro dos estudos a respeito da sua exposição no comportamento humano. Já que os jogos, produzidos em diversas partes do mundo, servem como um emissário cultural interativo, a psicologia deve interessar-se por seus efeitos no individuo, se estes podem ou não incitar comportamentos violentos e agressivos, uma vez que faz parte do repertório dos mesmos, de forma cada vez menos dependente de classe social.

\section{O fenômeno da agressividade}

Sobre agressividade, esta é um fenômeno de difícil estudo, explicação e compreensão, e seu conceito tal como se dá no senso comum difere-se daquele dado por teóricos das ciências sociais. De acordo com psicólogos, agressividade refere-se ao comportamento em que há intenção de danificar seja fisicamente, seja psicologicamente o outro, sendo ele objeto ou organismo. Tais psicólogos definem dois tipos de agressão: a hostil, que está relacionada a emoções fortes como raiva e tem por objetivo do indivíduo danificar o outro para satisfazer os seus instintos, e a instrumental, em que o indivíduo busca danificar o outro para atingir outros objetivos (Rodrigues, Assmar \& Jablonski, 2000).

Uma vez que a agressividade é um fenômeno social complexo, diversas explicações são apresentadas para estabelecer quais fatores têm impacto nesse tipo de comportamento. Rastreia-se os antecedentes do comportamento agressivo, seja focando-se em causas evolutivas, compartilhadas por toda a espécie (causas últimas), seja em diferenças individuais referentes ao funcionamento bioquímico e psicológico motivados pela história de vida do indivíduo e ou elementos presentes no ambiente (causas próximas). As explicações evolutivas estabelecem o porquê de indivíduos, de modo geral, se comportam de determinada forma e não de tantas outras formas possíveis (Kristensen, Lima, Ferlin, Flores \& Hackmann, 2003). De acordo com Niehoff (1999), a agressividade é resultado de um instinto de luta herdado que pertence não só aos seres humanos como também a outras espécies. Tal instinto é adaptativo e varia de acordo com as manifestações de cada idade e a escolha da vítima ou oponente, sendo que os indivíduos dispõem de mecanismos para inibir este instinto (Loeber \& Hay, 1997). Wilson (1975) estabelece a teoria da sociobiologia, em que os comportamentos agressivos se 
mantiveram ao longo das gerações por serem adaptativos, ou seja, favoreceram a transmissão dos genes dos indivíduos ao longo das gerações.

Muitos estudiosos partem da ideia de que o comportamento agressivo é aprendido e estabelecem como abordagem, duas formas como esta aprendizagem ocorre. A primeira é o principio da aprendizagem instrumental, que corrobora que todo e qualquer comportamento reforçado e recompensado tende a ocorrer mais vezes, assim como a agressividade, e o reforço para este comportamento ocorre em diversas circunstâncias, como quando gera aprovação social ou aumento do status, a recompensa do dinheiro dentre outros. Já de acordo com a abordagem da aprendizagem observacional, o individuo pode aprender novos comportamentos através da observação de outros indivíduos, os modelos, valendo assim também para agressividade (Bandura, 1973).

A cognição agressiva é citada por Burckley e Anderson (2006) como parte de um modelo geral de solução de problemas sociais. Para estes autores, uma ação social ocorre precedida de diversos fatores cognitivos e operações mentais que permitem uma resposta adaptada ao cenário que se impõe ao sujeito. A ação é, neste caso, função de crenças, expectativas e roteiros de comportamento que foram construídos ao longo da história de vida. As cognições agressivas antecedem, portanto, o comportamento agressivo e incluem um ensaio de possíveis estratégias comportamentais agressivas, bem como a aferição da provável eficiência dessas estratégias no cenário analisado. O videogame funciona como uma simulação de conflitos sociais muitas vezes apenas solúveis por ações agressivas e violentas, gerando uma aprendizagem que deixa a resposta agressiva saliente no sistema cognitivo e mais provável de ser ativada (Burckley \& Anderson, 2006).

O conceito de agressividade tal como apresentado anteriormente, não se estende à violência. O conceito de violência faz menção à atuação com uso da força de maneira abusiva, manifestação de desprezo pelo outro com ímpeto, objetivando causar dano extremo, agindo com opressão, violência, tirania, contra a vontade, liberdade e resistência de uma pessoa ou objeto, causando constrangimento físico e/ou moral (Barascut, 2006; Ferreira, 2001). Além disso, segundo Niehoff (1999), trata-se de um comportamento mal adaptativo de agressão direcionada ao oponente errado, com o lugar, a intensidade e o tempo também errados. Tais comportamentos são construídos socialmente e, estão presentes ao longo de toda a história da humanidade (Barascut, 2006; Rodrigues, Assmar \& Jablonski, 2000). Partindo deste principio, expor-se ao meio agressivo em geral, aumenta a probabilidade da agressividade e violência nos indivíduos porque a propagação da agressividade ocorre em grande parte através da aprendizagem, aplicação e ativação de estruturas relacionadas ao conhecimento da agressão que é armazenado na memória (Bandura, 1973; Zillmann, 1988).

\section{Agressividade no contexto midiático}

A exposição à agressividade se faz muito presente na mídia, como nos cinemas, programas de televisão, livros, jogos e filmes. Imagens e conteúdos violentos produzem processos psíquicos e emoções que de certa maneira impactam a função do contexto social para o indivíduo (Barascut, 2006). Desde os clássicos experimentos de Bandura (1963), o caráter de aprendizagem de comportamentos agressivos se faz presente. Em um destes experimentos, 
crianças do maternal observaram um adulto (o modelo), cada uma de uma vez. Este modelo realizava atos agressivos, tanto verbais quanto físicos em uma boneca. O outro grupo de crianças observou um modelo que ficava sentado na sala e não agredia a boneca. Posteriormente, foram submetidas a uma frustração leve e colocadas em uma sala com a boneca. As crianças tenderam a se comportar como o modelo. Aquelas que observaram o adulto agressivo deram mais respostas agressivas do que aquelas que observaram o adulto não agressivo (Hall, Lindzey \& Campbell, 2000).

Experimentos como este apresentam evidências de que a agressão que a mídia exibe pode acarretar em comportamentos e cognições agressivas, tais como hostilidade, comportamentos pró-violência e o aumento de crenças e atitudes a este respeito (Gentile \& Stone, 2005; Rodrigues, Assmar \& Jablonski, 2000). Apesar de não haver um consenso neste campo entre pesquisadores da área para que haja intervenções, muitos cientistas sociais se interessam pelo âmbito da agressividade em mídias. Monteiro (1984) realizou os primeiros experimentos a respeito dos efeitos nocivos destas mídias sobre os espectadores. A autora objetivou em sua pesquisa verificar os efeitos dos filmes com conteúdos violentos nos comportamentos agressivos de pré-adolescentes. Para este fim, os participantes assistiram a um filme violento e a um não violento. Foi concluído neste estudo que apesar dos préadolescentes terem afirmado sentir medo de vivenciar comportamentos violentos, quando expostos a uma situação experimental de agressão, a maioria se comportou agressivamente. Tais efeitos podem afetar o comportamento não só de adultos, como também de crianças e adolescentes (Ferreira, 2001). Nos Estados Unidos, Anderson e Bushman (2001) analisaram 8 horas de programas de televisão, concluindo que em cerca de $60 \%$ dos programas, há presença de conteúdos violentos. Yokota e Thompson (2000) analisaram o índice de violência em cenas de 74 desenhos animados, sendo estes classificados como destinados ao público em geral e concluíram que havia em todos, cenas de violência sendo que em $62 \%$ deles, de ferimentos fatais. Já Thompson e Haninger (2001) analisaram 55 jogos de computador considerados também como destinados a qualquer público, chegando à conclusão de que $64 \%$ envolviam violência intencional, dentro de uma média de 30,7\% de tempo jogando.

A partir dos experimentos de Bandura a respeito da tendência do individuo a executar os mesmos comportamentos agressivos de um modelo e a partir dos estudos de cientistas sociais sobre a quantidade de violência exposta nas mídias, especificamente nos videogames, levantase a problemática de se experiência com videogames agressivos ou a preferência pelos mesmos pode estar ligado às cognições agressivas.

\section{O videogame em seu âmbito histórico}

Acredita-se que o jogo sempre esteve presente em todos os processos culturais e que existe antes até mesmo da própria cultura, pensando no lúdico como uma peça fundamental para criação da música, poesia, rituais e até mesmo regras de guerra (Huizinga, 2000). O lúdico faz parte da cultura humana como um todo, não apenas restringindo-se à infância, pois ajuda o homem em seu processo de aprendizagem, em seu comportamento e em sua adaptação à realidade em todas as faixas etárias. De acordo com Huizinga (2000) a cultura humana se constitui com a existência de uma segunda realidade e como o jogo proporciona ao homem 
exercer um papel paralelo à realidade imediata, este se atrai pela ludicidade. Sua presença ocorre em diversas áreas sociais desde a economia, a partir do capital levantado pela indústria de jogos anualmente, gerando empregos e capacitação, até as relações sociais criadas por pessoas que têm interesses e comportamentos comuns a respeito de jogos. Este papel irreal pode ser ainda maior com os videogames, já que com a informática é possível simular praticamente qualquer tipo de atividade da realidade ou mesmo expandir esta realidade, oferecendo vivências em universos fantásticos e impossíveis (Abreu, 2003).

Com o surgimento dos videogames, iniciaram-se discussões e investigações a respeito dos seus possíveis efeitos no comportamento, afeto e cognição dos jogadores (Ferreira, Carneiro, Miguéis, Soares, \& Esteves, 2006). De acordo com Morais e Assis (2009) assim como os programas de televisão e as revistas em quadrinhos, os jogos eletrônicos são artefatos culturais inseridos como meios de comunicação em massa. Podem ser definidos como jogo em que há interação entre a pessoa que joga e as imagens transmitidas normalmente por um monitor ou tela de televisão. Para se jogar, são utilizados sistemas eletrônicos que combinam hardware e software, tais sistemas se encontram em computadores, consoles, fliperamas, videogames portáteis e celulares. A manipulação dos games é realizada através de um dispositivo chamado controle e a sua variação depende da plataforma. O jogador se torna protagonista de uma história e vivencia várias experiências, exigindo do mesmo diversas habilidades como as de solucionar problemas, criar estratégias e hipóteses (Alves et al., 2009).

A história dos videogames ocorreu de forma gradual e é bastante recente, tendo início há aproximadamente 50 anos (Ribeiro, Brunet \& Falcão, 2008). Nesta década, houve a primeira intenção de se criar um game, Willy Higinbotham inventou um jogo eletrônico de tênis, mas não o patenteou (Luna, 2008). Então, o primeiro jogo eletrônico patenteado surgiu em 1962 quando Stephen Russel criou Space War, considerado o primeiro videogame informático que na década seguinte seria aprimorado pelo engenheiro eletricista Nolan Bushnell que criou o primeiro fliperama do mundo (Ferreira et al., 2006). Bushnell contribui de maneira relevante para a história dos videogames ao fundar a empresa Atari e criar o jogo de fliperama Pong (Sellers, 2001).

Paralelo a tais acontecimentos, a década de 70 foi marcada pela criação do primeiro videogame conectado à TV, sendo estes denominados consoles. O primeiro game programável e possível de congelar, controlar a velocidade e o tempo, foi o Fairchild Channel F. Mas em 1980 estes consoles não mais vigoraram no mercado por causa do alto custo para o consumidor (Anderson \& Dill, 2000). O auge do consumo dos consoles ocorreu a partir de 1990, quando estes tiveram seus gráficos aperfeiçoados, os seus cartuchos passaram a possuir chips, garantindo maior realismo e ação nos jogos. Nos anos seguintes, lançaram-se consoles que além de compatibilizar jogos, realizaria leitura de DVD's, com capacidade de salvar músicas e sensores de movimentos.

A ascensão dos games com excessivo enredo antissocial ocorreu junto ao avanço dos mesmos, podendo-se citar o Grand Theft Auto, (grande ladrão de carros, em tradução livre) em que o personagem principal é um fora da lei que pode roubar todos os veículos e matar quantos personagens quiser. Ressalta-se ainda o jogo Carmageddon, que tem por objetivo atropelar e incendiar pessoas e animais, bater em inimigos e quebrar objetos nas ruas para que se ganhe 
pontos, sendo que quanto mais fizer destes atos e com mais estilo, mais pontos ganha, além do Motal Kombat, Resident Evil, Monhunt, dentre outros (Abreu, 2003; Luna, 2008).

A partir dessa ascensão, pesquisadores passaram a investigar o impacto dos jogos de videogame no âmbito da saúde, da coordenação viso-motora e da rotina diária dos jogadores (Ferreira, 2001). As opiniões dividem-se, principalmente entre sociólogos e psicólogos, que por sua vez afirmam que a violência exposta nos videogames ensina como agir, que a exposição a jogos violentos pode afetar negativamente o jogador e que jogar repetidamente aumenta comportamentos violentos porque afetam fatores cognitivos e a personalidade de quem joga (Bartholow, Sestir \& Davis, 2005). Por outro lado, como corroborado por Alves (2009), baseado na teoria da catarse, os games proporcionam ao jogador um espaço onde ele pode elaborar seus medos, ansiedades, tristezas e tantas outras emoções, sem transposição da tela. Todas estas questões levantadas a respeito dos games acarretaram na catalogação destes, de acordo com a idade apropriada para o conteúdo, o que acaba não impedindo que crianças e adolescentes tenham acesso a jogos impróprios para suas idades (Arriaga, 2000; Arriaga, Monteiro \& Esteves, 2008).

De acordo com Walsh (1999), dentre os gêneros dos jogos de videogames inseridos no mercado, como por exemplo, corrida, luta, esportes, simulação, estratégia, tiro e ação, uns dos mais consumidos são aqueles que apresentam características violentas e agressivas. Nos Estados Unidos e no Reino Unido, a NPD Group realizou em 2012 uma pesquisa apontando os dez jogos mais consumidos nestes dois países, sendo que o mais consumido foi um jogo de guerra com características extremamente violentas, o Call of Duty: Black Ops. Já no Brasil, de acordo com o IBOPE, 31\% dos jogadores preferem jogos de ação e aventura, seguidos por futebol (23\%) e corrida de carro (10\%). No que diz respeito ao perfil dos jogadores, são pessoas que geralmente se interessam por animações, quadrinhos, literatura, ficção e cinema. O IBOPE também lançou traços desde perfil, afirmando que a maioria dos jogadores brasileiros eram homens, tem entre 19 e 25 anos, preferiam o PlayStation como console, utilizavam Facebook e Twitter como mídias sociais e optavam por jogar em casa (Maciel, 2004).

\section{Estudos sobre os possíveis efeitos da exposição aos videogames no indivíduo}

$\mathrm{O}$ alto consumo de videogames trouxe consigo uma grande quantidade de pesquisas a respeito dos mesmos e o quanto estes podem afetar a vida dos seus jogadores, não só de maneira negativa. Pesquisas mostram que jogos de ação podem ser úteis no tratamento contra o câncer no campo do entendimento sobre a doença e do autocuidado no tratamento (Kato \& Beale, 2006). Foi observado também que um game educacional desenvolvido e jogado por crianças com leucemia falciforme, acarretou numa ampliação dos seus conhecimentos a respeito desta doença, aumentando a autoconfiança dos participantes (Yoon \& Godwin, 2007).

Dill e Dill (1998) afirmam que há uma correlação positiva entre jogar games violentos e se comportar de maneira agressiva. Krish (1998) investigou que há uma possível relação entre comportamento hostil imediato e jogar o game Mortal Kombat. Outras pesquisas mostraram que jogos violentos podem incentivar tanto comportamentos agressivos quanto delinquência, principalmente em homens e podem estimular comportamentos, cognições e sentimentos agressivos além de diminuir comportamentos pró-sociais (Anderson \& Bushman, 2001; 
Anderson \& Dill, 2000). De acordo com Barnett et al. (1999), o aumento da quantidade e frequência em que se joga, faz com que o indivíduo possa demonstrar preferência em jogar a realizar interações sociais. Por outro lado, pesquisadores afirmaram que a exposição a modelos simbólicos violentos pode habituar os indivíduos à violência e torná-los indiferentes ao sofrimento alheio (Linz, Donnerstein \& Penrod, 1987; Thomas, Horton, Lippincott \& Drabman, 1977). Além disso, evidências experimentais mostram que o contato com os jogos altamente ou suavemente violentos aumenta os pensamentos hostis de forma significante, acarretando também na extinção de respostas emocionais relacionadas à violência na vida real, causando assim um prejuízo na auto avaliação moral do indivíduo (Funk, Bushman, Jenks \& Bechtoldt, 2003).

Dois grupos de indivíduos jogaram jogos violentos e não violentos em estudo feito por Sestir e Bartholow (2010). Após jogarem, os participantes foram avaliados quanto à empatia, agressividade impulsiva e traços agressivos. Os participantes que jogaram os jogos violentos apresentaram um aumento em todas estas características quando comparados aos que jogaram os jogos não violentos. Os resultados encontrados em uma pesquisa realizada por Greitemeyer e Osswald (2011) foram ao encontro destes resultados. O objetivo dos pesquisadores foi verificar se videogames violentos aumentavam tendências agressivas e reduziam tendências pró-sociais. Os participantes foram divididos em dois grupos sendo que um grupo jogou um jogo pró-social e o outro grupo, um jogo violento. Percebeu-se que a exposição ao jogo pró-social relacionou-se positivamente a comportamentos pró-sociais por parte dos jogadores e aqueles que jogaram o jogo violento apresentaram menos comportamentos de empatia e mais satisfação quando outra pessoa estava passando por problemas. Posteriormente, um estudo longitudinal com duração de três anos foi realizado por Ferguson et al. (2012) com o objetivo de averiguar se a agressividade em jovens seriam consequências da exposição a videogames violentos. Os participantes responderam a um questionário a respeito dos jogos favoritos e os que mais jogavam quando as coletas foram feitas, uma escala a respeito de eventos negativos do cotidiano, além de ter sido verificado pelos pesquisadores histórico de depressão e de violência na família dos indivíduos. Nesta pesquisa, foi concluído que a exposição a videogames com conteúdos violentos não se relacionou com qualquer resultado negativo verificado, como depressão, agressividade ou comportamentos antissociais.

Um problema encontrado na literatura consultada foi a escassez de estudos nacionais que investigassem se indivíduos que jogam videogames violentos apresentam mais cognições agressivas comparativamente aos sujeitos que não jogam videogames deste gênero ou não jogam qualquer videogame. Portanto, a presente pesquisa teve por objetivo verificar a relação entre a preferência por conteúdos violentos e hábitos relacionados aos jogos de videogames com a tendência a cognições agressivas. A hipótese aqui levantada foi que uma exposição alta a conteúdos violentos nesse tipo de mídia estaria relacionada com uma priorização cognitiva de conteúdo com carga semântica ligada a atos de agressividade. Essa hipótese relacional encontra suporte em resultados de pesquisas anteriores que sugerem um impacto causal entre a exposição a conteúdos violentos em videogames e agressividade (Buckley \& Anderson, 2006).

Além disso, objetivou-se descrever os hábitos de jogo dos participantes e a violência média geral nos jogos recentes e preferidos; investigar a relação entre os hábitos de jogo e a preferência por videogames com diferentes conteúdos; averiguar a relação entre características 
sócio demográficas, hábitos de jogo e cognições agressivas e relacionar o nível de violência explícita nos videogames preferidos com tendência a cognições agressivas.

\section{Método}

No presente estudo foi realizado um estudo relacional. Nesse tipo de investigação, observa-se a relação entre as variáveis, sem que haja uma manipulação das mesmas por parte do pesquisador.

\section{Participantes}

Compuseram o grupo amostral desta pesquisa 102 participantes, sendo 56 homens e 46 mulheres, com idades variadas entre 18 a 49 anos, média de 24 anos e desvio padrão de 4,77. Destes participantes, 33 não jogavam e 69 jogavam. Quanto ao sexo dos jogadores, percebeu-se que no geral, 52 eram homens, seguido de apenas 17 mulheres, o que retoma a um dos apontamentos feitos em websites sobre jogos de que a indústria de videogames é geralmente composta por homens, assim como a maioria dos jogadores. Tal informação se confirma também através da pesquisa feita pelo IBOPE a respeito do perfil dos jogadores brasileiros, em que retrata que no país $47,1 \%$ dos jogadores são do sexo feminino.

\section{Procedimento de coleta de dados}

Para participar do estudo, era necessário que os participantes tivessem conta na rede social Facebook, pois o contato inicial e a divulgação do instrumento foram feitos através da mesma. O link do Google Docs foi postado na rede e compartilhado entre os usuários, sendo que para responder ao instrumento era necessário clicar neste link. Os indivíduos foram convidados a participar do estudo através da divulgação do link postado em grupos sobre videogame, da postagem no perfil do Facebook da própria pesquisadora e pelo compartilhamento da postagem entre os amigos da mesma. Foi ressaltado que poderia participar da coleta apenas aqueles que fossem maiores de idade, mas não era necessário que o individuo fosse jogador de videogame.

\section{Materiais}

Para a coleta dos dados foram utilizados o termo de consentimento livre e esclarecido, questionário sócio demográfico - sexo e idade dos participantes - e o instrumento de levantamento de cognições criado no aplicativo online Google Docs. O instrumento de coleta é de elaboração própria, tendo sido idealizado e confeccionado para coleta de dados da presente pesquisa. Para que o nome do instrumento não induzisse respostas relacionadas ou não à violência, o nome apresentado no Google Docs a quem respondesse foi "Questionário de Habilidades Ortográficas". 


\section{Cognições agressivas}

O instrumento foi dividido em duas etapas: A primeira objetivava avaliar cognições agressivas, então apresentava 12 conjuntos de letras no qual cada um deles apresentava-se numa sequencia com uma lacuna a ser completada. Os 12 conjuntos de palavras foram: $S$ _CO, CH_T_,_APA, _IRO, F_CA,_O_TE, BR_GA, R_IVA,_ALA, _URRO,_ANC_DA e RE_OL_ER. A tarefa do participante consistia em preencher estas lacunas com letras do alfabeto, de maneira que formasse uma palavra, por exemplo, S_CO, cabendo as respostas SACO, SUCO, SOCO ou SECO. Considerou-se para a tabulação dos dados cognições agressivas sempre que a palavra fizesse referencia a contextos de violência, então no exemplo citado, SOCO seria indicativo de cognição agressiva mais acessível que uma não agressiva.

\section{Hábitos de jogo}

Foi questionado se os participantes jogam ou não jogos de videogame, os que responderem que não jogam, não avançaram para a sequência de questões do questionário. Por fim, as perguntas seguintes foram relacionadas a hábitos de jogo e foram dispostas posteriores às palavras de completar para evitar o possível priming de jogos violentos. Sobre priming entende-se como um rótulo verbal, em que se supõe que ao ser apresentado ao indivíduo, são mais acessíveis à memória itens relacionados a esse rótulo, mesmo que de forma inconsciente (Pereira, 2002).

A segunda etapa do instrumento teve por objetivo analisar hábitos de jogo, então foi primeiramente perguntado com que frequência o participante joga videogame e quando joga, quantas horas por dia. Posterior a esta etapa, foram apresentadas afirmativas nas quais o participante deveria marcar uma resposta dentro da escala likert com as alternativas de resposta: 1) Discordo totalmente; 2) Discordo em parte; 3) Neutro; 4) Concordo em parte e 5) Concordo em totalmente. As afirmativas foram as seguintes: "Quando jogo videogame, costumo perder a noção do tempo"; "É comum não ouvir o que outra pessoa fala quando estou jogando"; "Costumo pensar nos jogos quando não estou jogando"; "Videogame costuma ser assunto de conversa entre amigos.

A coleta foi realizada em ambiente virtual, através da divulgação do instrumento na rede social Facebook. O presente estudo foi aprovado pela Comissão de Ética em Pesquisa envolvendo seres Humanos (CEPES), conforme o Memorando № 003/2014/UFSJ/CEPES.

\section{Análise de dados}

Para se calcular a frequência dos jogos citados pelos participantes, estes foram primeiramente classificados em uma das seguintes categorias: Sem inimigos ou mortes; com inimigos, mas com mortes estilizadas ${ }^{4}$; mortes com sangue no inimigo; mortes com muito sangue espalhado pelo cenário; desmembramentos, feridas abertas e mutilações.

\footnotetext{
${ }^{4}$ Entende-se como estilizadas, quando os personagens jogam poderes nos oponentes e não aparece sangue na tela, mas sim, brilhos coloridos ou luzes.
} 
A cognição agressiva foi calculada com base nas palavras formadas ao se completarem as lacunas no instrumento. Um escore de agressividade foi gerado atribuindo 1 ponto a cada palavra que fizesse referencia a situações agressivas. Este escore poderia, portanto, variar de 0 a 1, (já que o instrumento contava com 12 palavras a serem formadas) sendo 0 para nenhuma palavra agressiva e 12 para todas as palavras agressivas.

Neste estudo foram utilizadas duas análises estatísticas para discutir as variáveis. A estatística descritiva, para as variáveis tempo de jogo, jogos preferidos, jogos que tem jogado recentemente e violência exposta nestes jogos.

A estatística inferencial foi utilizada para relacionar diferentes variáveis. Foi utilizado o teste de correlação de Spearman para analisar padrão de distribuição dos seguintes pares de variáveis: Tempo de jogo com violência dos jogos preferidos; frequência semanal com violência dos jogos preferidos; idade com frequência em que se joga; tempo de jogo com cognições agressivas; frequência semanal com cognições agressivas; violência exposta nos jogos preferidos com cognições agressivas; violência exposta nos jogos recentes e cognições agressivas.

Para comparar a diferença das médias de homens e mulheres com relação à frequência semanal que se joga, foi utilizado o teste t de Student.

\section{Resultados}

\section{Hábitos de jogos}

Em relação a hábitos de jogos, foi questionada a frequência em que os participantes jogavam videogame, conforme Tabela 1.

Tabela 1- Frequência em que se joga videogames

\begin{tabular}{lc}
\hline Frequência & Participantes \\
\hline Quase nunca & 6 \\
Um dia na semana & 12 \\
Dois dias na semana & 14 \\
Três dias na semana & 7 \\
Quatro dias na semana & 3 \\
Cinca dias na semana & 9 \\
Praticamente todo dia & 23 \\
\hline Total & $\mathbf{7 4}$ \\
\hline
\end{tabular}

A tabela 1 mostra que seis destes quase nunca jogavam, 12 jogavam um dia na semana, 14 jogavam dois dias, sete três vezes por semana, três quatro dias por semana, nove cinco dias na semana, e 23, que foi a maioria da amostra, jogavam praticamente todos os dias.

Ainda a este respeito, foi perguntado aos participantes o tempo de jogo nos dias eu que jogava como mostra a Tabela 2. 
Tabela 2 - Tempo de jogo nos dias em que joga

\begin{tabular}{lc}
\hline Horas & Participantes \\
\hline Mais ou menos meia hora & 2 \\
Uma hora & 14 \\
Duas horas & 30 \\
Três horas & 10 \\
Quatro horas & 9 \\
Cinco horas ou mais & 9 \\
\hline Total & $\mathbf{7 4}$
\end{tabular}

Por meio da Tabela 2 pode-se observar uma maior concentração de jogadores que dedicavam duas horas por dia para jogar (30), seguidos dos jogadores com dedicação de uma hora (14), seguido dos que jogavam 3 horas (10), quatro horas (9), cinco horas ou mais (9) e dois participantes jogavam mais ou menos meia hora.

Dezesseis dos participantes que jogam diariamente dedicavam duas horas ou mais a essa atividade, sugerindo que o videogame se configura para parte considerável da amostra como uma atividade bastante presente em seu cotidiano e potencialmente influente. A exposição de mais de duas horas a esse tipo de conteúdo midiático indica uma importância em se investigar tanto a natureza desse conteúdo quanto os potenciais efeitos da exposição.

A Tabela 3 diz respeito às respostas quando afirmado que os participantes costumam perder a noção do tempo quando jogam.

Tabela 3 - Costuma perder a noção do tempo quando joga

\begin{tabular}{lc}
\hline Concordância & Participantes \\
\hline Discordo totalmente & 4 \\
Discordo em parte & 7 \\
Neutro & 10 \\
Concordo em parte & 31 \\
Concordo totalmente & 22 \\
\hline Total & 74 \\
\hline
\end{tabular}

Neste caso, apenas quatro dos participantes discordaram totalmente, sete discordaram em parte, dez não tinham uma opinião formada a este respeito, classificando-se como neutros, 31 concordaram em parte e 22 concordaram totalmente.

Embora se trate apenas de relato e não de um efeito concluído experimentalmente, a atenção dispensada à atividade destaca-se, uma vez que parece distorcer a percepção do tempo. O alto potencial de entretenimento também pode ser inferido desse efeito. Provavelmente a natureza interativa da mídia e sua constante demanda por tomadas de decisão impõe um consumo mais ativo e uma maior preocupação com uma eventual derrota no jogo. 
Na questão seguinte, foi afirmado que eles não costumam ouvir o que outra pessoa fala quando está jogando, como mostra a Tabela 4.

Tabela 4 - Costuma não ouvir o que outra pessoa fala quando está jogando

\begin{tabular}{lc}
\hline Concordância & Participantes \\
\hline Discordo totalmente & 7 \\
Discordo em parte & 23 \\
Neutro & 10 \\
Concordo em parte & 22 \\
Concordo totalmente & 12 \\
\hline Total & 74 \\
\hline
\end{tabular}

Percebeu-se que sete dos participantes discordaram totalmente com a afirmação de que costumam não ouvir o que outra pessoa fala quando está jogando, 23 discordaram em parte, 10 não tinham uma opinião formada a respeito, classificando-se como neutros, 22 concordaram em parte e 12 concordaram totalmente.

O comprometimento da vigilância para estímulos alheios à atividade de jogo não é relatado com tanta frequência quanto o déficit da competência para avaliar a passagem do tempo, mas ainda assim, mais da metade dos participantes com opinião sobre o efeito relatou tê-lo experimentado.

A Tabela 5 mostra as frequências de resposta quando afirmado que os participantes costumam pensar em jogos quando não estão jogando.

Tabela 5 - Costuma pensar em jogos quando não está jogando

\begin{tabular}{lc}
\hline Concordância & Participantes \\
\hline Discordo totalmente & 14 \\
Discordo em parte & 15 \\
Neutro & 14 \\
Concordo em parte & 20 \\
Concordo totalmente & 11 \\
\hline Total & $\mathbf{7 4}$ \\
\hline
\end{tabular}

Neste caso, 14 dos participantes discordaram totalmente, 15 deles discordaram em parte, 14 não tinham uma opinião formada a respeito, classificando-se como neutros, 20 concordaram em parte e 11 concordaram totalmente.

A este respeito de quando afirmado que os participantes costumam conversar com os amigos sobre videogame mesmo quando não estão jogando, notou-se que três dos participantes discordaram totalmente quando afirmado que os videogames costumam ser o tema das conversas com os amigos, sete discordaram em parte, 19 não tinham uma opinião 
formada a respeito, classificando-se como neutros, 27 concordaram em parte e 18 concordaram totalmente.

A penetração do hábito de jogo na vida de grande parte dos participantes é bastante notável. Além de haver uma dedicação considerável à atividade, o momento de jogo é encarado com muita atenção e à atividade é dada uma importância tal que aspectos do jogo acompanham os jogadores em seus pensamentos mesmo em outros momentos do dia. Essa relevância é reforçada pelo hábito de se ter jogos e seu conteúdo como assunto para conversas em eventos sociais diversos. A exposição aos conteúdos presentes nos videogames não apenas se dá por longos períodos de tempo, como parece gerar interesse e fomentar a troca de experiências entre aqueles que se dedicam aos jogos.

\section{Violência e hábitos de jogo}

Com relação ao nível de violência em jogos ao qual o participante se encontrava exposto, foram coletados dados de modo a formular duas variáveis. A primeira relativa à violência de jogos recentemente jogados e a segunda relativa à violência presente nos jogos preferidos pelos participantes.

Tanto para os jogos que mais recentemente têm jogado quanto para os jogos preferidos, calculou-se um escore de violência exposta para cada variável. Para isto, as respostas foram analisadas atribuindo pontos a cada jogo que fosse classificado de acordo com as 5 categorias estabelecidas - 0 pontos para a categoria sem inimigos ou mortes, 1 ponto para com inimigos, mas com mortes estilizadas, 2 pontos mortes com sangue no inimigo, 3 pontos mortes com muito sangue espalhado pelo cenário e 4 pontos para a categoria desmembramentos, feridas abertas e mutilações. Os escores de cada jogo foram então somados para que se obtivesse o escore geral. Como foi pedido aos jogadores que nomeasse cinco jogos em cada uma das duas variáveis, estes escores poderiam variar de 0 a 20, sendo 0 para nenhum jogo agressivo e 20 para todos os jogos com grau máximo de violência. Nos jogos recentes, obteve-se uma média de 8,62 jogos violentos, com desvio padrão de 4,54. A respeito da preferência por games com conteúdos violentos, obteve-se média de 8,66 de violência nos jogos e desvio padrão de 4,20.

Apenas quatro participantes tiveram entre seus jogos mais recentes um conteúdo livre de mortes sangrentas contra 56 que foram expostos a pelo menos um jogo em que havia a presença de mortes e sangue. Em relação ao jogo preferido, apenas três participantes listaram exclusivamente jogos sem sangue contra 55 que tinham entre seus jogos preferidos ao menos um que contava com mortes e sangue. A exposição à violência nos jogos experimentada pela amostra é bastante evidente, embora tenha havido uma variação na quantidade de violência e sua gravidade.

Para analisar a relação entre as variáveis, foram utilizados métodos quantitativos específicos para cada uma destas. Todos os objetivos tiveram como alvo variáveis relativas aos hábitos de jogo (tempo e frequência em que se joga), que por sua vez foi examinado junto a outras de acordo com cada objetivo. Com as variáveis tempo de jogo com violência nos jogos preferidos, utilizou-se o teste de Correlação de Spearman, por as variáveis serem discreta e ordinal. Não houve uma correlação significativa $(\rho=0,07, p=0,60)$, ou seja, não houve relação 
entre o tempo que se joga e a preferência por games violentos. O mesmo teste foi utilizado para as variáveis frequência com violência nos jogos preferidos, por estas serem também variáveis ordinal e discreta. Em seu resultado houve uma correlação significativa, porém fraca $(\rho=0,33$, $p=0,01$ ), o que significa que houve uma relação, mesmo que fraca, de que quanto maior a frequência que se joga, maior a preferência por jogos violentos.

Foi utilizado o Teste t Student para analisar as variáveis sexo com frequência em que se jogava. Como resultado, não houve uma diferença significativa $t(67)=1,57, p=0,12$, mostrando que não houve uma relação entre o sexo dos participantes, com a frequência em que se jogava. A média de frequência masculina foi de 4,60, estando o intervalo de confiança (95\%) entre 3,98 e 5,21. A média de frequência feminina foi de 3,65, estando o intervalo de confiança (95\%) entre 2,62 e 4,67. Não houve diferença significativa entre o tempo de jogo e a idade dos participantes, $\rho=0,00, p=0,97$ (teste de Correlação de Spearman), ou seja, não houve relação entre a idade dos jogadores e a duração que estes jogavam videogames.

\section{Cognições agressivas}

Outra variável investigada são as cognições agressivas em que se obteve uma média de 5,43 cognições agressivas (versões violentas das 12 palavras completadas), com desvio padrão de 3,03 .

A Tabela 6 apresenta os resultados das correlações entre cognições agressivas e hábitos de jogo. A variável cognição agressiva foi primeiramente relacionada com tempo de jogo e como resultado, através da utilização do teste de Correlação de Spearman, observou-se que não houve correlação significativa $(\rho=-0,02, p=0,87)$. Não houve relação entre o tempo em que se jogava com cognições agressivas. Posteriormente, foi relacionada com frequência, sem correlação significativa como resultado $(\rho=-0,21, p=0,08)$, não havendo então relação entre frequência em que se jogava e cognições agressivas. Também não houve correlação significativa na relação entre cognição agressiva e violência nos jogos preferidos $(\rho=-0,17, p=0,22)$, assim como não houve na relação entre esta e violência nos jogos recentes $(\rho=-0,05, p=0,70)$. Estes dois resultados mostram que não houve relação entre jogar games violentos, bem como preferir estes tipos de games com as cognições agressivas.

Tabela 6 - Correlações entre hábitos de jogo e cognições agressivas

\begin{tabular}{lllll}
\hline Medidas & Tempo de jogo & $\begin{array}{l}\text { Violência nos jogos } \\
\text { preferidos }\end{array}$ & Frequência de jogo & $\begin{array}{l}\text { Violência em jogos } \\
\text { recentes }\end{array}$ \\
\hline Cognições Agressivas & $\rho=-0,02$ & $\rho=-0,17$ & $\rho=-0,21$ & $\rho=-0,05$
\end{tabular}

Nota: Nenhuma significância estatística foi encontrada nessas correlações.

Os dados sugerem que a exposição interativa à violência, ainda que intensa e frequente não está relacionada à cognição agressiva, expressa pela saliência cognitiva de palavras violentas. 


\section{Discussão}

As cognições agressivas foram a variável norteadora dos objetivos desta pesquisa, tendo sido analisada em relação aos hábitos de jogo e natureza dos jogos a que os participantes foram expostos. Verificou-se que as relações esperadas a partir do objetivo principal, a saber, entre cognições agressivas e exposição a conteúdo violento não foram confirmadas. Segundo o modelo teórico previsto, pessoas mais expostas à violência interativa típica dos videogames estariam mais propensas a completar palavras ambíguas com versões violentas que aquelas pouco expostas a essa violência.

Ao contrario dos resultados obtidos nesta pesquisa, existem diversos estudos a respeito da exposição dos games violentos no comportamento dos indivíduos, estudos estes que vão de encontro aos resultados obtidos no presente estudo. A partir dos resultados de outras pesquisas, afirmou-se que a agressão exibida na mídia pode acarretar em comportamentos e cognições agressivas, tais como hostilidade, comportamentos pró-violência e o aumento de crenças e atitudes a este respeito (Gentile \& Stone, 2005; Rodrigues, Assmar \& Jablonski, 2000). Afirmou-se ainda que a exposição a games violentos afeta negativamente o jogador, que 0 contato com os jogos altamente ou suavemente violentos, aumenta os pensamentos hostis de forma significativa (Funk, Bushman, Jenks, \& Bechtoldt, 2003). Outros autores ressaltaram que este tipo de jogo aumenta os comportamentos violentos porque afetam fatores cognitivos e na personalidade de quem joga e que tais jogos estimulam comportamentos, cognições e sentimentos agressivos além de diminuir comportamentos pró-sociais (Anderson \& Bushman, 2001; Bartholow, Sestir \& Davis, 2005).

É possível sugerir algumas hipóteses ao se contrastar os resultados aqui encontrados com aqueles observados na literatura. Primeiramente, grande parte da amostra relatou alguma exposição à violência de modo que embora o efeito não escale com a quantidade e intensidade da violência, ainda é possível que um efeito "tudo ou nada" exista, o que estaria fora das possibilidades dessa amostra, já que poucas pessoas estavam isentas de experimentar mortes com sangue em seus jogos recentes e preferidos.

Além disso, a saliência cognitiva de termos violentos é apenas uma das consequências possíveis de uma mudança na cognição agressiva. Uma série de outras alterações comportamentais poderia também ser alvo de investigação, incluindo expectativas sociais a respeito das intenções alheias ou avaliação de soluções agressivas ou não para conflitos.

Os objetivos propostos mais descritivos foram satisfatoriamente alcançados. Foi possível construir um perfil de hábitos de jogo bastante consistente apesar de algumas limitações. A raridade de jogadores que experimentam jogos, mas estão livres de uma exposição a violência realista foi um achado interessante. A violência enquanto conteúdo não está restrita a alguns jogos ou a algum gênero, mas bastante disseminada nos jogos mais populares e valorizados pelos participantes. Esse dado sugere que envolver-se com videogames trará, em algum momento, um contato com um conteúdo violento explícito, especialmente, levando-se em conta que a experiência é comumente acompanhada de discussões com outras pessoas a respeito dos jogos, o que deve gerar sugestões de novas experiências. 
A maioria da amostra na presente pesquisa foi do sexo masculino, mas não houve relação entre a preferência por videogames violentos e cognições agressivas dentro desse grupo. Este dado vai de encontro à pesquisa que mostrou que jogos violentos podem incentivar tanto comportamentos agressivos quanto delinquência, principalmente em homens (Anderson \& Dill, 2000). Essa discrepância sugere que o efeito maior da exposição de jogos violentos pode ser temporário. Jogar, deste modo, serviria como priming de um viés cognitivo em direção a conteúdos e modelos de ação agressivos e antissociais.

\section{Conclusões}

A partir desta pesquisa, pode-se concluir que não houve relação entre videogames violentos e cognições agressivas. Grande parte dos resultados coletados a partir da amostra não apresentou relação entre as variáveis, apesar de que uma delas (frequência com preferência por jogos violentos) ter apresentado uma fraca relação. Não houve o controle para outras mídias violentas, como TV, cinema, e como estas podem também estar ligadas às cognições agressivas, este fator pode ter influenciado nos resultados e pode ter sido uma limitação neste estudo.

Uma hipótese a ser levantada é a de que o efeito da exposição a jogos violentos seja apenas momentâneo, o que o tornaria indetectável pela presente pesquisa, uma vez que não houve controle do tempo passado entre a sessão de jogo e a resposta ao instrumento. A possibilidade de outro estudo onde os participantes responderiam ao instrumento de forma imediata à exposição dos jogos, poderia apresentar diferentes resultados com possível relação entre as variáveis estudadas.

Grande parte das pesquisas encontradas aponta para a ideia de que a exposição a videogames violentos pode afetar, principalmente negativamente, no comportamento humano. O fato de esta pesquisa ter ido de encontro à maioria dos teóricos citados não a invalida, mas sim, enriquece ainda mais a literatura a respeito dos jogos eletrônicos e possibilita o levantamento de questionamentos a partir dos resultados. Ao se observar que a maioria dos participantes que jogavam, costumavam perder a noção do tempo, pensar em jogos mesmo quando não estavam jogando e conversar com amigos a respeito deste tema mostra como é importante que se considere as consequências da exposição aos videogames no comportamento humano, não necessariamente de forma negativa.

O presente estudo apresentou a limitação relacionada ao método adotado para a seleção dos participantes. Os indivíduos foram selecionados para compor a amostra por terem tido acesso à postagem feita no Facebook. Logo, nem todos os sujeitos da população alvo puderam compor a amostra, como por exemplo, jogadores de videogame que não possuem conta na rede social Facebook ou que não tiveram acesso à postagem. Como a amostra desta pesquisa não é representativa da população alvo, os resultados aqui encontrados apresentam a sua generalização limitada. Apesar da limitação apontada, foi possível através da presente pesquisa, ampliar o corpo de conhecimentos a respeito da relação entre os videogames de conteúdos violentos e cognições agressivas. A escassez de estudos nacionais a respeito desta temática justifica e mostra a relevância da realização desta pesquisa. 


\section{Referências}

Abreu, A. (2003). Videogame: Um bem ou um mal? Um breve panorama da influência dos jogos eletrônicos na cultura individual e coletiva. Recuperado de http://www.andredeabreu.com.br/docs/videogames_bem_ou_mal.pdf.

Alves, L. (2009). Eletrônicos e Violência: O retorno 2009. Rua - UFSCAR, 1, 2232-2233.

Alves, L., Carvalho, A., Silveira, J., Belizário, J., Fortini, M., Costa, D., Gomes, E., Costa, R., \& Bambirra, E. (2009). Videogame: suas implicações para aprendizagem, atenção e saúde de crianças e adolescentes. Revista Médica de Minas Gerais, 19(1), 19-25.

Anderson, C., \& Bushman B. (2001). Effects of Violent Video Games on Aggressive Behavior, Aggressive Cognition, Aggressive Affect, Physiological Arousal and Prosocial Behavior: A Meta-Analytic Review of the Scientific Literature. Psychological Science, 12, 353-359. doi: 10.1111/1467-9280.00366.

Anderson, C., \& Dill, E. (2000). Video Game and Aggressive Thoughts, Feelings and Behavior in the Laboratory and in Life. Journal of Experimental Social Psychology, 78, 772-790. doi: http://dx.doi.org/10.1037/00223514.78.4.772.

Arriaga, P. (2000). Violência nos videojogos e a agressividade: estudo exploratório da associação entre jogar videojogos violentos e a agressividade em adolescentes. Dissertação de mestrado, Instituto Superior de Psicologia Aplicada, Lisboa, Portugal.

Arriaga, P., Monteiro, M., \& Esteves, F. (2008). Fatores mediadores e moderadores dos efeitos dos jogos eletrônicos violentos na agressão interpessoal. Revista Portuguesa de Pedagogia, 42(2), 203-223.

Bandura, A. (1963). The role of imitation in personality. The Journal of Nursery Education, 18(3), 207-215.

Bandura, A. (1973). Aggression: A social learning analysis. Englewood Cliffs, New Jersey: Prentice-Hall.

Barascut, P. (2006). Violências Midiáticas. Revista FAMECOS, 29, 135-138.

Barnett, M. A., Vitaglione, G. D., Harper, K. K. G., Quackenbush, S. W., Steadman, L. A., \& Valdez, B. S. (1999). Late Adolescents Experiences and Attitudes Toward Video Games. Journal of Applied Social Psychology, 27, 13161334. doi: 10.1111/j.1559-1816.1997.tb01808.x.

Bartholow, B., Sestir, M., \& Davis, E. (2005). Correlates and consequences of exposure to video game violence: hostile personality, empathy, and aggressive behavior. Personality and Social Psychology Bulletin, 31, 15731586. doi: 10.1177/0146167205277205.

Buckley, K., \& Anderson, C. (2006). A Theoretical model of the effects and consequences of playing video games. In P. Vorderer \& Bryant. Playing Video Games - Motives, Responses, and Consequences (pp. 363-378). Mahwah, NJ: LEA.

Dill, K., \& Dill, J. (1998). Video game violence: a review of the empirical literature. Agression and Violent Behavior, $4(3), 407-428$.

Ferguson, C., Miguel, C., Garza, A., \& Jerabeck, J. (2012). A longitudinal test of video game violence influences on dating and aggression: A 3-year longitudinal study of adolescents. Journal of Psychiatric Research, 46(2), 141-146.

Ferreira, P. (2001). Violência (Ir)real? Contributo para uma reflexão acerca do impacto da violência dos jogos eletrônicos nas crianças e nos jovens. Caleidoscópio, 4, 95-106.

Ferreira, P., Carneiro, M., Miguéis, M., Soares, S., \& Esteves, F. (2006). Jogos de Computador violentos e seus efeitos na hostilidade, ansiedade e ativação fisiológica. Lisboa Rev.. Lusófona de Ciências de Mente e do Comportamento, 193-210. 
Funk, J., Bushman, D., Jenks, J., \& Bechtoldt, H. (2003). Playing Violent Video Games, Desensitization and Moral Evaluation in Children. Applied Developmental Psychology, 24, 413-436. doi: org/10.1016/S01933973(03)00073-X.

Gentile, D., \& Stone, W. (2005). Violent video game effects on children and adolescents - A review of the literature. Minerva Pediátrica, 57, 337-358.

Greitemeyer, T., \& Osswald, S. (2011). Playing Prosocial Video Games Increases the Accessibility of Prosocial Thoughts. The Journal of Social Psychology, 151(2), 121-128. doi: 10.1080/00224540903365588.

Hall, C., Lindzey, G., \& Campbell, J. (2000). Albet Bandura e as Teorias da Aprendizagem Social. In C. Hall, G. Lindzey \& J. Campbell. Teorias da Personalidade (4a ed., pp. 459-476). Porto Alegre, Rio Grande do Sul: Artmed.

Huizinga, J. (2000). Homo Ludens: o jogo como elemento da cultura (4⿳亠口冋 ed.). São Paulo: Perspectiva.

Kato, P., \& Beale, I. (2006). Factors affecting acceptability to young cancer patients of a psychoeducational videogame about video. Journal of Pediatric Oncology Nursing, 23, 269275. doi: $10.1177 / 1043454206289780$.

Kirsh, S. (1998). Seeing the world through Mortal Kombat-colored glasses: Violent video games and the development of a short-term hostile attribution bias. Childhood: A Global Journal of Child Research, 2, $177-$ 184. doi: 10.1177/0907568298005002005.

Kristensen, C., Lima, J., Ferlin, M., Flores, R., \& Hackmann, P. (2003). Fatores etiológicos da agressão física: uma revisão teórica. Estudos de Psicologia, 8, 175-184. doi: 10.1590/S1413-294X2003000100020.

Linz, D., Donnerstein, E., \& Penrod, S. (1987). Sexual violence in the mass media: Social psychological implications. In P. Shaver \& C. Hendrick. Review of personality and social psychology (7ạ ed., pp. 95-123). Beverly Hills: Sage Publications.

Loeber, R., \& Hay, D. (1997). Key issues in the development of aggression and violence from childhood to early adulthood. Annual Review of Psychology, 48, 371-410. doi: 10.1146.

Luna, D. (2008). Comunicação e representação social nos videogames - Em análise o jogo Grand Theft Auto-San Andreas. Revista Eletrônica Temática, 4(7), 1-34.

Maciel, M. (2004). O desenho nos jogos eletrônicos. 13ํEncontro Nacional da ANPAP. Brasília, DF.

Monteiro, M. (1984). La construction sociale de la violence: approche cognitive et developpementale. Tese de doutorado, Universidade Católica de Lovaina, Lovaina, Bélgica.

Morais, W., \& Assis, R. (2009). Os jogos eletrônicos: Artefatos culturais, tecnológicos e virtuais na sociedade da era digital. Recuperado de http://www.senept.cefetmg.br/galerias/Arquivos_senept/anais/terca_tema5/TerxaTema5ArtigA12.pdf.

Niehoff, D. (1999). The biology of violence. Nova York: Free Press.

Pereira, M. E. (2002). Psicologia social dos estereótipos. São Paulo: EDU.

Ribeiro, J. C., Brunet, K., \& Falcão, T. (2008). Comunicação móvel e jogos em espaços híbridos. Revista da Associação Nacional dos Programas de Pós-Graduação em Comunicação, 11(2), 1-15.

Rodrigues, A., Assmar, E., \& Jablonski, B. (2000). Comportamento antissocial: A agressão. In A. Rodrigues, E. Assmar \& B. Jablonski. Psicologia Social (19ạ ed., pp. 203-244). Petrópolis, Rio de Janeiro: Vozes.

Sellers, J. (2001). Pong. In J. Sellers. Arcade Fever: The Fan's Guide to the Golden Age of Video Games (pp. 16-17). Philadelphia: Running Press.

Sestir, M. A., \& Bartholow, B. D. (2010). Violent and nonviolent video games produce opposing effects on aggressive and prosocial outcomes. Journal of Experimental Social Psychology, 46, 934-942.

Thomas, M., Horton, R., Lippincott, E., \& Drabman, R. (1977). Desensitization to portrayals of real-life aggression as a function of exposure to television violence. Journal of Personality and Social Psychology, 35, 450-458. doi: org/10.1037/0022-3514.35.6.450. 
Thompson, K., \& Haninger, K. (2001). Violence in E-rated video games. The Journal of the American Medical Association, 286, 591-598. doi:10.1001/jama.286.5.591.

Walsh, D. (1999). Video and computer game report card. Recuperado de http:// www.mediaandthefamily.org/1999vgrc2.html.

Wilson, E. (1975). Man: From sociobiology to sociology. In E. Wilson. Sociobiology: The new synthesis (pp. 547-575). Cambridge, United States: Harvard University Press.

Yoon, S., \& Godwin, A. (2007). Enhancing self-management in children with sickle cell disease through playing a CDROM educational game: A pilot study. Pediatric Nursing, 33, 60-63. doi: 17411004.

Yokota, F., \& Thompson, K. (2000). Violence in Grated animated films. The Journal of the American Medical Association, 283, 2716-2720. doi:10.1001/jama.283.20.2716.

Zillmann, D. (1988). Cognition-excitation interdependencies in aggressive behavior. Aggressive Behavior, $14,51-64$. doi: org/10.1002/1098-2337.

Apresentação: 12/05/2015

Aprovação: 30/11/2015 